
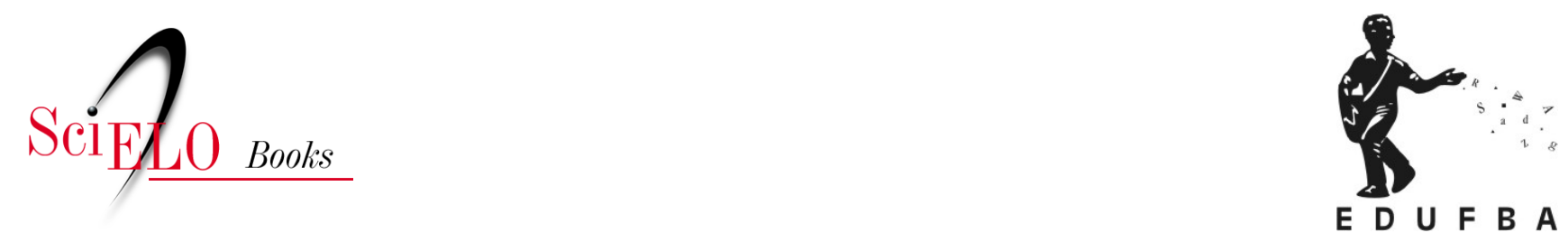

\title{
Contribuição na formação educacional, cultural, profissional e de filosofia de vida
}

\author{
Hellio Campos
}

\section{SciELO Books / SciELO Livros / SciELO Libros}

CAMPOS, H. Contribuição na formação educacional, cultural, profissional e de filosofia de vida. In: Capoeira regional: a escola de Mestre Bimba [online]. Salvador: EDUFBA, pp. 196-203. ISBN 97885-232-1727-3. Available from: doi: 10.7476/9788523217273.0017. Also available in ePUB from: http://books.scielo.org/id/p65hq/epub/campos-9788523217273.epub.

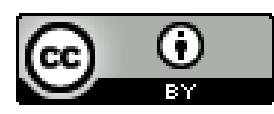

All the contents of this work, except where otherwise noted, is licensed under a Creative Commons Attribution 4.0 International license.

Todo o conteúdo deste trabalho, exceto quando houver ressalva, é publicado sob a licença Creative Commons Atribição 4.0. 


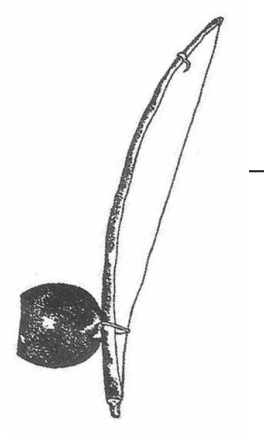

Contribuição na formação educacional, cultural, profissional e de filosofia de vida

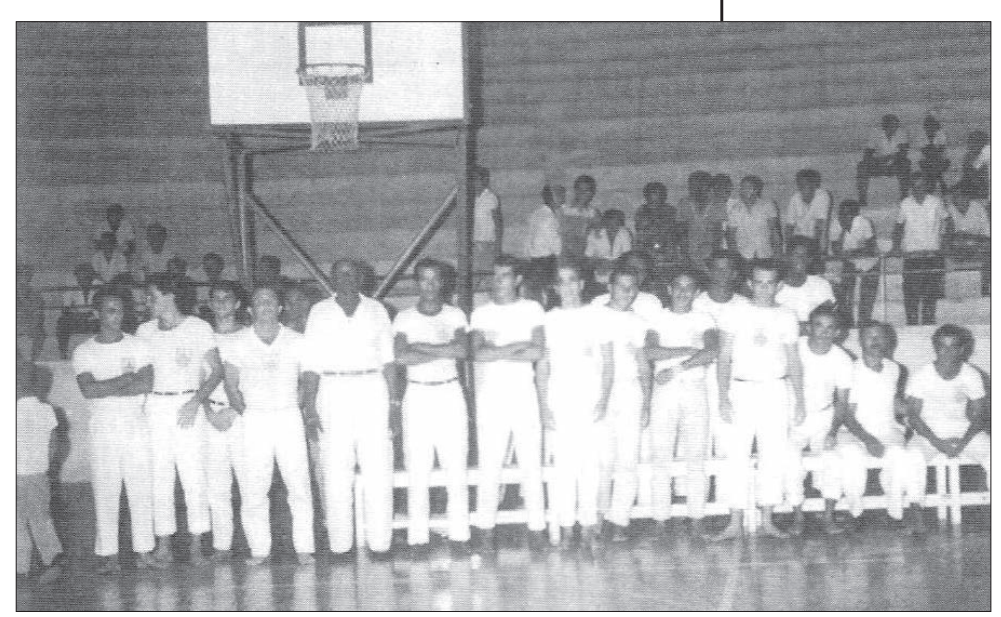


Q erá que houve uma efetiva contribuição dos ensinamentos de Mestre Bimba para
a formação educacional, cultural, profissional e até mesmo na filosofia de vida dos seus alunos? A partir deste questionamento buscamos entender de que maneira tal contribuição aconteceu, qual a verdadeira influência da Capoeira Regional, da relação dos alunos com Bimba e da convivência dos diferentes colegas no curso de Capoeira Regional.

São bastante controversas as informações sobre o perfil de Mestre Bimba: uns afirmam ser ele um autoritário, disciplinador, embrutecido, uma pessoa sem instrução formal, que era rude, chegando a ser grosseiro no tratamento com seus alunos, mas outros tantos referem-se ao mestre como uma pessoa que usava da autoridade, embora sem apresentar na sua conduta um autoritarismo, relacionando-se de modo amigável, e se dedicando a um relacionamento individualizado, de acordo a personalidade de cada um de seus alunos.

\section{Cafuné assim explica o seu relacionamento com Bimba:}

Eu sentia um carinho muito grande dele com relação a minha pessoa. Tanto que ele brincava muito comigo com relação ao meu apelido, não só nas aulas com os colegas que faziam brincadeiras com relação a isso, mas sempre brincadeiras de cunho carinhoso e isso era uma característica muito dele, gostava muito quando ele colocava a mão no meu ombro para falar alguma coisa, quando eu tava por perto e ele colocava a mão no meu ombro e fazia as palestras dele, e ele fazia isso com todos, não era só comigo. Quando havia shows e exibições dele, do grupo que eu participava ele contava a história do meu apelido, ele contava que uma suposta noiva minha chegava lá e reclamava dele, Mestre por que o senhor colocou esse apelido nele e ele explicava que eu era muito tímido, que ele fez aquilo para mexer comigo, aí ele fazia sempre uma brincadeira que a mulher achava que era por outra coisa e tal, e era sempre essa relação de amizade, muito próxima de carinho mesmo (sic).

\section{Cafuné, além disso, se reporta à contribuição da Capoeira Regional em sua vida.}

Principalmente pessoal, porque eu era uma pessoa que só olhava para o chão, eu tinha medo de olhar para frente, eu tinha uma dificuldade de me relacionar com as pessoas, para eu arranjar uma namorada eu tinha que levar dois, três amigos para a gente sair para eu procurar uma namorada, no emprego, meu primeiro trabalho meu irmão mais velho que me arranjou, eu nunca tinha saído e depois da Capoeira Regional eu levantei a cabeça e vi que tinha horizonte à frente, que eu podia dar um passo, sem precisar de outras pessoas, acho que a coisa mais importante que a Capoeira Regional fez na minha cabeça eu acredito que tenha sido esta (sic).

\section{Medicina assim comenta:}

Na formação educacional, me deu perseverança para o meu ser; na cultura, me iniciou no aprendizado e a cultuar o que se refere à cultura baiana e brasileira; na profissional, porque aprendi muito sobre medicina popular (que ele conhecia como poucos) e pude adaptar à medicina alopata que aprendi na Faculdade e com os meus clientes. Até hoje utilizo seus ensinamentos (apesar da globalização e do avanço acelerado da biotecnologia) sobre sua filosofia de vida, que foi uma coisa pessoal, intrínseca e mística. Aprendi a exercer responsabilidade social (muito em moda atualmente) desde que conheci o Mestre Bimba que já tinha esta 
prática no seu dia-a-dia, cito como por exemplo a convivência benemerente com os moradores da rua das Laranjeiras, no Pelourinho, com as prostitutas e seus filhos, entre outras (sic).

\section{Gato Branco fala da autoconfiança:}

Eu posso fazer assim uma analogia a respeito do que a Capoeira me proporcionou, basicamente enfocando um aspecto, o aspecto da autoconfiança e de saber que a gente, se quiser, a gente pode, as coisas a gente consegue, porém, como eu era um menino franzino apesar da boa estatura, bom porte para a prática da Capoeira Regional, mas eu não me achava capaz de chegar no estágio que eu cheguei naquela época, aos três anos e meio a quatro anos de jogar Capoeira, com a desenvoltura como eu joguei, isso me deu a autoconfiança que tem me acompanhado na minha vida laborativa, inclusive nas funções que eu tenho e tive, por que na vida tudo é uma disputa, vem disputando funções e nessas disputas a gente vai para o enfretamento, sabendo que a gente pode conseguir as coisas. Eu, fazendo uma analogia o que a Capoeira me ofereceu, eu acho que o aspecto da autoconfiança foi muito importante e também na minha função gerencial, que foi a função que norteou toda minha atividade laborativa, como gerente já se vão mais de vinte e cinco anos, eu tive a oportunidade de, no banco, enfrentar clientes desaforados, arrogantes que as vezes tentavam me intimidar, por não atender um crédito, não atender uma solicitação que no ponto de vista técnico não podia e as vezes o cara se sentia magoado, isso aconteceu algumas vezes; tá certo, apesar da gente engolir muito sapo, mas a gente tem de se impor, a gente se impunha e reagia a um desaforo, a gente reagia porque sabia que existia por trás toda uma confiança de que a coisa não podia ser daquela maneira, então basicamente a autoconfiança que a capoeira me deu, ela vem me acompanhando ao longo da vida, no enfrentamento das questões (sic).

\section{Sariguê conta do sentimento de carinho que Bimba demonstrava por ele:}

Ah, isso inclusive, ele tinha um jeito carinhoso. O mestre, até o jeito dele ser carinhoso era diferente. Mas você sentia quando ele fazia alguma colocação, ele tinha costume de chegar, sempre que tinha um batizado, sempre que tinha uma apresentação lá, ele me chamava no centro e dizia: esse menino que chegou aqui, as costas dele só dava um palmo da minha mão, hoje em dia dá dois palmos da minha mão, a mãe dele nunca trouxe uma latinha de leite para o mestre, e eu me sentia super envaidecido, porque o mestre tinha um jeito de mostrar para você, que ele gostava de você, sem ele dizer, eu gosto de você, são pequenos detalhes que fazem a diferença. No grupo dele, eu fui convidado porque, fazer parte do grupo do mestre era uma honra, eu acho que chegar ao máximo na academia do mestre era fazer parte do grupo dele, e além de eu fazer parte do grupo dele, meu jogo era a chave de ouro.

Sariguê enfoca que Bimba e a Capoeira Regional foram determinantes na sua formação como homem: "com certeza, eu costumo dizer que a capoeira, ela foi decisiva em toda a minha vida, não foi só na minha vida profissional não, em toda a minha vida como cidadão" (sic); frisa asseverando que "a capoeira que eu aprendi, que foi a capoeira do Mestre Bimba, que tinha tudo isso, tinha aquele conceito que é realmente uma arte marcial, então quando eu fui fazer as outras atividades, eu já vim preparado pelo Mestre Bimba" (sic).

Itapoan fala da relação de Mestre Bimba com seus alunos, assegurando que ele gostava de conversar e que ele somente dava ordens quando estava ensinando.

Pois é, tinha alunos que ele conversava e se dava muito bem, contava piadas e falava da vida dele tudo em fatos. Ele só dava as ordens nas aulas, como todo ensinamento é assim, a gente também como professor, tem alunos que a gente trata melhor, quando a gente nota que um aluno é muito interessado a gente faz tudo por aquele aluno, agora o outro não muito interessado a gente faz o trivial. O Mestre Bimba era assim, se você era um aluno interessado, ele descobria que você estava interessado e começava a te dar coisas, e também falava muito por, tipo assim não por parábolas, mas quase isso ele dava toques, se você pegasse legal, se você não pegasse, ele não ia te explicar de novo. Então ele era uma figura direta assim, mas tinha uma amizade muito grande com a gente, um carinho muito grande pelos alunos dele (sic).

Essa maneira de conversar com seus alunos, já apontada anteriormente por outros entrevistados e autores, demonstra o carinho e a maneira peculiar de Mestre Bimba passar seus ensinamentos, que tinha como principal motivação o conteúdo da capoeira, contudo se estendia, abarcando outros assuntos, a exemplo da sua história de vida, dos movimentos 
capoeirísticos da época, das lições por parábolas e da conversa bem-humorada. Galo ressalta esse momento, dizendo ser uma imagem sempre presente na sua mente: "ele botava os pés pra cima e ficava batendo papo com a gente, contando suas histórias, ensinava a gente a refletir sobre os passos da capoeiragem, sem a necessidade de usar as pernadas".

Ao prefaciar o livro "A saga de mestre de Bimba", de Mestre Itapoan, assim me expresso:

César Itapoan foi um dos alunos mais brilhantes da Academia, e logo cedo despertou enorme interesse em conhecer algo mais sobre a Capoeira, muitas vezes presenciei, e até peguei carona das suas longas conversas com o mestre, onde o assunto palpitante versava, entre outros, da origem à atualidades da Capoeira e Capoeiristas (sic).

Muniz Sodré também se refere ao assunto das lições, dizendo que Bimba era um sábio e que "não duvidaria que, nele, às vezes 'baixasse' algo como uma entidade chamada São Salomão" (2002, p. 72). Lembra-se das extraordinárias lições, afirmando que "o mestre admitia implicitamente que só se permanece na mudança, que os filhos crescem na morte simbólica dos pais, que a aprendizagem criativa comporta a possibilidade de ultrapassagem da maestria".

Itapoan diz que a Capoeira Regional faz parte da sua vida, tomou conta do seu corpo por inteiro, que as lições de Bimba o ensinaram a entender por que "o vizinho enricou sem trabalhar" e por que "o senhor trabalhou tanto e nunca pôde enricar" e a compreender "a volta que o mundo dá", certificando-se a cada dia "que o mundo dá muitas voltas", por isso se sente contemplado e agradece dizendo: "um dia você me ensinou que a ginga é a alma do capoeirista. Eu ainda tô gingando mestre, eu ainda tenho a ginga 'Seo' Bimba. Mestre, obrigado, que bom que tive berço".

Galo atesta que a sua passagem pela Capoeira Regional e a estreita convivência com Mestre Bimba trazem uma contribuição muito forte para a sua formação; refere-se, ainda, a um trabalho que está em andamento, intitulado "Capoeiragem: a arte de gingar com vida", pelo qual tenta traduzir o nível de influência da Capoeira Regional em sua vida e seu cotidiano, inclusive a repercussão disso na sua vida profissional, em uma área específica das ciências médicas, ou seja, a medicina veterinária. Conta que durante os seus estudos de doutorado, em Medicina Veterinária, na Alemanha, na cidade de Hannover, os ensinamentos da capoeira o ajudaram muito na convivência e na resolução das adversidades próprias da adaptação climática e de uma nova cultura. Lembrava todo o tempo de uma frase de Mestre Bimba: "meu filho, recuar também é golpe". Hoje, esta frase é quase que um lema, sendo repetida sempre, em momentos oportunos, para os filhos, funcionários, colegas, alunos e amigos. É um ensinamento que suscita uma reflexão nas ações do cotidiano, do pensar e agir.

Para Sacy, "o mestre impunha uma segurança, ele, por si só, era o líder dentro da sala de aula. Com o mestre, nós aprendíamos a respeitar os mais velhos, os professores, os mestres, os seus pais. Ele dava a lição sem precisar dizer a você que era pra fazer aquilo".

Disse ainda: "ninguém tinha intimidade para falar com o mestre batendo no seu ombro. O respeito sempre se fazia presente e o limite era considerado". Revela que nenhum aluno 
tinha a ousadia de mexer no berimbau que ficava preso na parede. Sacy verdadeiramente se refere ao respeito que Bimba impunha, pela sua postura e pelo relacionamento com seus alunos. Disse mais: "Mestre Bimba era uma pessoa introvertida, somente aparecia ser extrovertido durante os dias de festas, formatura e batizados. Parece que se transformava nos eventos, pois nas aulas tinha uma atitude fechada". Comenta que "seu método era tão eficaz que pouco se dirigia aos alunos durante as aulas. Os alunos de Bimba já sabiam do que o mestre gostava e do que não gostava".

Sacy certifica que o relacionamento de Bimba era sensorial; ele ditava as ordens por mensagens, por gestos e por olhar. "Os alunos eram 'obrigados' a observar o mestre, ele era um ser supremo ali na sua academia".

Para Boinha, a convivência com Mestre Bimba influenciou de maneira marcante a sua formação educacional:

Sim, eu garanto que se você entrevistar os milhares de alunos de Mestre Bimba, todos vão falar a mesma coisa. Lá a gente aprendia pela disciplina, porque em casa com o pai e mãe a gente relaxa, a gente não obedece. Quando o mestre olhava para você, pronto, era motivo de você se consertar logo. Essa influência na formação moral da pessoa era muito importante. Aprendi a esperar, o mestre dizia a fruta só dá no tempo, você aprendia a ser tolerante. Mestre Bimba me ensinou a viver pela disciplina, fazia a gente pensar. Ele chamava atenção, dava conselhos. Se você obedecia a ele, você obedecia a seu pai, sua família, aprendia a ter mais amor pela família (sic).

Nos depoimentos dos entrevistados, podemos observar que praticamente todos comentaram de suas experiências durante o estreito relacionamento com Mestre Bimba, e da real contribuição dos ensinamentos do mestre na formação pessoal. Como era de se esperar, cada um foi tocado de maneira diferente e fica impossível avaliar a intensidade com que este toque despertou algo em cada sujeito. Com certeza, essa experiência modificou esses capoeiristas, segundo os depoimentos, para melhor, considerando os aspectos que eles relataram, como a questão da disciplina, da tolerância, do carinho, da segurança, da autoconfiança, do despertar para a questão cultural e, sobretudo, do respeito.

\section{A CONVIVÊNCIA ENTRE OS DIFERENTES NA ACADEMIA DE MESTRE BIMBA}

Em alguns dos depoimentos apresentados, foi levantada a questão da arte do relacionamento, que os informantes destacaram como sendo um aprendizado de singular valor para suas vidas, adquirido na roda da Capoeira Regional, no seio da academia de Bimba. Perguntamos, então, como era a convivência dos diferentes, no Centro de Cultura Física Regional? Este questionamento se justifica, não apenas pelas citações dos seus alunos, mas, sobremaneira, por sabermos de antemão que o CCFR era frequentado por indivíduos de estratos sociais diferenciados, níveis de instrução variados, questões culturais, variedade étnica, o forte e o fraco, o hábil e o inábil, o alto e o baixo, o corajoso e o medroso, o adulto e o adolescente, o rico e o pobre, o letrado e o iletrado e pessoas com opções religiosas e políticas bem matizadas. 
Para Escurinho, a convivência dos diferentes era saudável, pois não existiam diferenças dentro da academia: "não tinha segregações de negro, de branco, de rico ou de pobre; a diferença você tirava tecnicamente na roda e, se a coisa pegasse, o mestre intervinha e separava, sem tomar partido".

Galo disse que "não tinha diferença, sinceramente não me lembro", e que "se Mestre Bimba tratava mal alguém não tinha diferença de cor, de raça e logicamente ele, como uma pessoa muito inteligente que foi, estabeleceu um nível dos seus alunos, como um nível de estudantes, o que é outro ensinamento dele" ( $\mathrm{sic}$ ). Ele não queria alunos que não tivessem futuro, exigia que fossem estudantes e o tratamento era nivelado. "O que realmente chamava atenção era que ele não aceitava o desrespeito, e eu vi Mestre Bimba botar para fora da academia por, principalmente, uso e abuso de força em determinados golpes, ou pelo mau caráter de quem estava jogando". E lembra de um fato pitoresco, de "um aluno que estava jogando na roda e deixou cair o canivete, demonstrando fraqueza e desonestidade ao ir para a roda armado. Mestre Bimba colocou para fora o aluno e nunca mais eu o vi na academia". Para Galo, este fato evidencia uma outra importante lição de Bimba.

Já, Gato Branco, comenta o assunto da seguinte maneira:

Bom! Uma das coisas que eu me lembro bem nas preleções do mestre, é que ele fazia questão de dizer que ali na academia não existia diferença de classe social, isso com o palavreado dele e a maneira dele colocar as coisas. Tá certo, que não existiam diferenças, que todos éramos iguais, tá certo, evidentemente você convivia com pessoas mais pobres de uma classe social mais baixa, mais ali dentro existia uma irmandade, uma coisa, ali. O diferente que você coloca, era diferente na cor, na classe social, no nível de escolaridade, mas lá dentro nos tornávamos iguais e a convivência era a melhor possível, a gente convivia, na hora da brincadeira a gente estava brincando, na hora da amargura, a gente era solidário, tá certo, acho que isso aí foi muito importante para a gente, porque a gente convivia com pessoas desiguais, como você está dizendo, mas na hora da prática da Capoeira todos eram iguais perante a lei e a lei era a Capoeira (sic).

Para Medicina, a convivência dos diferentes era:

Desconfiada para os que não eram da sua academia e para os diferentes (que entendo que sejam os que não compreendiam suas ordens e ensinamentos) era grosseiro e não pedia a ninguém quaisquer conselhos como agir com aqueles indivíduos. Tomava a atitude que achava acertada de imediato, podendo chegar a extremos; ex: expulsar o aluno (ou diferente) da sua academia (sic).

Cafuné trata da questão, dizendo que "dentro da academia, no momento que a gente estava lá dentro, a gente não tinha muita diferença não, ali nós formávamos um mundo, a gente não sentia essas diferenças não (sic)". No entanto, faz alusão ao relacionamento de Mestre Bimba com alguns de seus alunos:

Ele tinha admiração por algumas pessoas, como Decânio, por exemplo, que era uma pessoa que tinha uma participação muito grande na vida dele, que o ajudava muito e tinha outras pessoas que o ajudavam de certa maneira, essas pessoas tinham um pouco mais de aproximação com ele, e os mais antigos que tinham mais liberdades que nós os novos e nós fomos adquirindo isso aos poucos, então eu não via assim uma discriminação do pobre, do negro, do branco, não tinha essa coisa tão clara assim, o que existia era umas pessoas que ajudavam o mestre, que tinham mais aproximação, tinham um pouco mais de liberdade com ele, mas ele tinha um carinho muito grande com aquele que chegava desde o primeiro momento quanto tinha também com o Decânio (sic).

Segundo Sariguê:

[...] o mestre, ele tinha critérios, ou seja, o aluno tinha que estudar ou trabalhar, então muitas vezes o aluno trabalhava, mas não tinha uma condição social, nem econômica, nem cultural, mas com isso, ali dentro não havia diferença, não havia discriminação, por que atenção ele dava para todos, e quanto mais aquele aluno 
era interessado, claro, tinha mais acesso ao mestre, então não tinha discriminação de forma nenhuma, como muitas pessoas imaginam (sic).

Nenel diz que as diferenças não se consolidavam "devido à presença equilibrada de Bimba; por esse motivo e uma atitude firme e segura do mestre, as pessoas aprendiam a respeitar os limites de cada um".

Para Itapoan, "a escola de mestre Bimba era uma grande irmandade, uma coisa muito bonita, onde o treinar para melhorar era o lema e ninguém queria ser, nem se achava, melhor que ninguém" (2005, p. 96). O principal objetivo era treinar, e a consequência natural era ficar bom de capoeira, pois não existia a idéia de virar mestre de capoeira e sim ficar cada vez melhor, cada vez mais capoeirista.

Geni inicia dizendo que as pessoas que não conheceram Bimba afirmam ser ele um indivíduo racista, mas ele discorda dessa afirmação, pois, baseado em suas observações, entende que o mestre deve ter sofrido muita discriminação por ser negro e semi-analfabeto. Diz que quando conheceu Bimba, ele era muito bem aceito nos lugares aonde ia e também muito respeitado.

Na Academia de Mestre Bimba diziam que não tinha preto, tinha sim, eu conheci alguns e convivi de perto com eles. Também frequentavam a Academia pessoas de diversas classes sociais, lógico sendo que a maior parte era de estudantes de colégios e jovens universitários. Vale ressaltar, que Bimba vivia como mestre de Capoeira e por esse motivo foi o primeiro a organizar uma escola, o Centro de Cultura Física Regional. Posso dizer claramente que eu nunca senti nenhuma discriminação na Academia. Lá todo mundo vivia em igualdade, independente do credo, opção política e condição social (sic).

Sacy assim se expressou: "rapaz, na academia de Mestre Bimba não tinha diferença, lá todos eram iguais. Éramos uma família, não havia segregação de classe social e religião. Lá não havia diferentes, todos eram iguais e viviam em uma democracia plena".

Arara lembra da existência de grupos diferenciados durante os horários de treinamento. No horário da manhã, treinavam aqueles que trabalhavam. No horário da tarde era a vez dos estudantes e no horário da noite treinava o grupo de elite bem mesclado. "A academia de Mestre Bimba tinha uma semente de elite, os estudantes universitários, isso a fez ser um diferencial entre outras academias de capoeira". Lembra que Bimba tinha o cuidado de não aceitar crianças para treinamento de Capoeira Regional e a idade média girava entre 16 a 20 anos. Contudo, nas aulas sempre tinha a presença de alunos formados, com idades bem avançadas. "Lá existia uma irmandade e se cultivava a amizade, ninguém podia mexer com os alunos de Bimba, era mexer em um enxame de abelhas".

Boinha concorda com a existência de diferentes classes sociais, opções religiosas e políticas, no entanto ninguém era melhor que ninguém, era uma convivência irmanada e o amigo lá dentro da academia era amigo fora, na rua, sempre amigo.

Certo é que todos os alunos que foram batizados por Mestre Bimba na Capoeira Regional deixaram de ser pessoas comuns, passaram a figurar entre os privilegiados por terem sido alunos de Bimba.

Mestre Bimba pregava na sua academia que todos eram irmãos, sentimento esse vivido na atualidade, vivido no hoje, quando dos encontros, quer nas rodas de capoeira, quer em outros locais recreativos ou mesmo profissionais. A lembrança de ter sido aluno de Bimba 
funciona como uma senha, abrindo portas e facilitando o relacionamento. Esse sentimento de irmandade impulsiona para uma boa comunicação e uma relação fraterna, a exemplo da vivida na escola de Bimba.

Observamos durante as entrevistas um brilho nos olhos e uma expressão de contentamento nos sujeitos da Capoeira Regional. Eles denotavam espontaneamente que a convivência dos diferentes fora de uma riqueza sem precedentes para as suas vidas, talvez pelo principal aprendizado de valorizar as pessoas, reconhecendo seus potenciais e limitações, mas, sobretudo, respeitando-os nas suas individualidades. 